Journal of Antimicrabial Chemotherapy (1990) 25, 689-695

\title{
Incidence of gallbladder lithiasis after ceftriaxone treatment
}

\author{
A. Cometta", S. Gallot-Lavallée-Villars", A. Iter", L. Cantoni", A. Anderegg \\ J. J. Gonvers and M. P. Glauser \\ 'Division des Maladies Infectieuses, CHUV; ${ }^{b}$ Service de Radiologie, CHUV; \\ 'Policlinique Médicale Universitaire, Lausanne, Switzerland
}

\begin{abstract}
Ceftriaxone has potent activity against a broad range of Gram-positive and Gramnegative bacteria. While it is eliminated mainly by the kidney, $10-20 \%$ of the drug is eliminated in the bile and ceftriaxone salt precipitates have been described in the gallbladder of animals dosed with ceftriaxone. The purpose of the present study was to investigate the incidence of biliary lithiasis 6 and 12 months after treatment with ceftriaxone and to compare it with that in patients treated with amoxycillin/ clavulanate. Biliary ultrasonography was performed at the start of treatment, at 6 months and at 12 months after the beginning of the study. One hundred patients were randomized and 74 were evaluable: 34 were given amoxycillin/clavulanate, 40 ceftriaxone. Gallbladder lithiasis developed in one patient 12 months after the amoxycillin/clavulanate treatment and in none in the ceftriaxone treatment arm. Biliary precipitate during ceftriaxone treatment was not looked for because this phenomenon was not known at the beginning of the study, but gallbladder precipitation that was seen in two patients given ceftriaxone during and at the end of treatment, respectively, resolved spontaneously.

In conclusion, ceftriaxone treatment does not appear to lead to gallstone formation more often than an antibiotic that is not eliminated through the bile.
\end{abstract}

\section{Introduction}

Ceftriaxone has demonstrated potent activity against a broad range of Gram-positive and Gram-negative bacteria (Cleeland \& Squires, 1984). Its long half life allows once-aday administration (Patel \& Kaplan, 1984; Baumgartner \& Glauser, 1983). This property has permitted the use of ceftriaxone in a variety of bacterial infections including pneumonia, biliary and urinary tract infections, endocarditis, meningitis and gonococcal infections.

While ceftriaxone is mainly eliminated in the urine, $10-20 \%$ of the drug is eliminated in the bile (Hayton, Schandlik \& Stoeckel, 1986; Hayton \& Stoeckel, 1986; Brogard et al., 1987). Observations in dogs and monkeys (Teelmann, Schärer \& Udaka, 1982) have cocasionally shown precipitation of the calcium salt of ceftriaxone in the gallbladder after prolonged intravenous administration. In humans, precipitation during or after ceftriaxone administration has been described. In a young patient population, gallbladder ultrasonography demonstrated that the precipitation disappeared after completion of treatment (Schaad, 1986; Schaad \& Tschãppeler, 1987). Nevertheless, concerns have been raised that this accumulation may lead to gallstone formation. 
The purpose of the present study was to investigate the incidence of biliary lithiasis 6 and 12 months after treatment with ceftriaxone and to compare it with that in patients treated with amoxycillin/clavulanate. This latter antibiotic combination was chosen because it has indications similar to those for ceftriaxone, while its biliary concentration is negligible and biliary lithiasis has not been reported to develop in association with its use.

\section{Method}

\section{Patients}

Patients who presented a documented bacterial infection which required antibacterial therapy fo: more than seven days were eligible for the study. Patients were excluded if they had had a cholecystectomy, known biliary lithiasis, an allergy to $\beta$-lactam antibiotic:, renal insufficiency with a creatinine clearance $<10 \mathrm{ml} / \mathrm{min}$, an infection with an $0:$ ganism that was resistant to ceftriaxone or amoxycillin/clavulanate, or were pregnant.

Oral informed consent was obtained from the patient. The trial was approved by the Ethics Committee of the hospital.

\section{Experimental design}

This was a prospective open randomized study. Patients received either ceftriaxone $2 \mathrm{~g}$ once-a-day or amoxycillin/clavulanate 1.2 g $4-6$ times a day.

\section{Clinical and routine laboratory data}

Upon entry into the study, the patient's history was obtained and a physical examination performed which was repeated during the trial and at the end of the treatment. Before beginning therapy, blood for culture (two sets) was taken, as well as samples from the site of infection. In addition, haemoglobin, haematocrit, leucocyte count, differential blood count, creatinine, blood urea nitrogen, total bilirubin, ASAT, ALAT, alkaline phosphatase, cholesterol and triglycerides were measured in all patients at study entry, as well as on days 3,7 , and at the end of treatment.

Biliary ultrasonography was performed at the time of randomization and at 6 and 12 months after the entry into the study, with a Phillips Sono Diagnost B, Diasonics ds-J or Hitachi EUB-25 with transducers of 3.5 and $5 \mathrm{MHz}$. The physician (AA) who performed the ultrasonography did not know which antibiotic the patient had received.

The gallbladder was scanned through its long axis from a lower intercostal and/or preferably subcostal approach. The plane of section was swept medially and laterally to allow visualization of the entire volume of the gallbladder. Gallbladder lithiasis was considered to be present when an intraluminal echo with an acoustic shadow was detected. In some cases, many small calculi did not show an acoustic shadow but their presence could be confirmed when the intraluminal echoes moved with changes in patient position. Gallbladder sludge and precipitation were defined as intraluminal echoes forming a fluid-fluid level that moved very slowly with change in patient position, without producing a postacoustic shadowing (Cooperberg \& Gibney, 1987). 


\section{Statistical analysis}

Differences between the two groups were tested for significance by Student's test (age and treatment duration), Fisher's test (sex, infections by site and organisms, gallbladder lithiasis) and Chi-square test (Dunnet \& Gent, 1977).

\section{Results}

One hundred patients were randomized in this study; 49 received ceftriaxone and 51 amoxycillin/clavulanate. Twenty-six were excluded from the evaluation for various reasons. Four patients died before the first control evaluation at six months; a 24 year old man committed suicide; a 70 year old woman died of cardiac insufficiency; a 76 year old man died of gastrointestinal hemorrhage; and a 75 year old man died of a cerebral hemorrhage. Seventeen patients did not attend for ultrasonography at 6 and 12 months; ten patients' practitioners were called and confirmed that these persons had developed no biliary symptoms during the year following the end of the antibiotic treatment. In two of these ten, a sonography of the gallbladder performed at three months was normal. No details were obtained in seven patients. Two patients had antibiotics for less than seven days and two received further treatment with amoxycillin/clavulanate and/or ceftriaxone during the follow-up period. One patient was randomized but should have been excluded because he had a cholecystectomy two years before the study.

Demographic data from the 74 patients who could be evaluated are shown in Table I. The mean age of the ceftriaxone group was slightly higher than amoxycillin/clavulanate, but this difference was not statistically significant. The distribution of infections by site and organisms is summarized in Table II. Urinary tract $(51 \%)$, pulmonary tract $(16 \%)$ and ENT $(9.5 \%)$ infections were the most frequent infectious sites treated. The infective microorganisms were mainly Escherichia coli, which represented $50 \%$ of the microbiologically documented infections.

Gallbladder lithiasis or precipitation was seen in five patients belonging to the ceftriaxone group and in five patients in the amoxycillin/clavulanate group (see

Tabte I. Demographic data-evaluable patients

\begin{tabular}{|c|c|c|c|}
\hline & $\begin{array}{l}\text { Amoxycillin/ } \\
\text { clavulanate } \\
(4-6 \times 1.2 \mathrm{~g} / \mathrm{d})\end{array}$ & $\begin{array}{l}\text { Ceftriaxone } \\
(2 \mathrm{~g} / \mathrm{d})\end{array}$ & $P$ \\
\hline $\begin{array}{l}\text { Patients' number } \\
\text { man } \\
\text { woman }\end{array}$ & $\begin{array}{l}34 \\
11 \\
23\end{array}$ & $\begin{array}{l}40 \\
20 \\
20\end{array}$ & $0-09$ \\
\hline $\begin{array}{l}\text { Age (years) } \\
\text { median } \\
\text { average ( } \pm \text { s.D.) } \\
\text { range }\end{array}$ & $\begin{array}{c}42 \\
44 \cdot 2( \pm 19 \cdot 4) \\
17-78\end{array}$ & $\begin{array}{c}52 \\
51 \cdot 4( \pm 18 \cdot 8) \\
20-77\end{array}$ & $\begin{array}{l}0-09 \\
0.11\end{array}$ \\
\hline $\begin{array}{l}\text { Treatment duration (days) } \\
\text { median } \\
\text { average ( } \pm \text { S.D.) } \\
\text { range }\end{array}$ & $\begin{array}{c}14 \\
16.8( \pm 10-4) \\
7-59\end{array}$ & $\begin{array}{c}11 \\
17.6 \underset{7-87}{( \pm 16-2)}\end{array}$ & $\begin{array}{l}0.28 \\
0-82\end{array}$ \\
\hline
\end{tabular}

S.D., Standard deviation. 
Table II. Distribution of infections by site and organisms

\begin{tabular}{lrr}
\hline & $\begin{array}{c}\text { Amoxycillin/ } \\
\text { clavulanate }\end{array}$ \\
& & \\
\hline Site & & 23 \\
Urinary & 15 & 6 \\
Pulmonary & 6 & 2 \\
ENT & 5 & 3 \\
Sepsis & 4 & 6 \\
Others & 4 & \\
Organisms & & 15 \\
E. coli & 16 & 3 \\
Klebsiella sp. & 1 & 3 \\
Proteus sp. & 0 & 7 \\
Streptococcus & 3 & 3 \\
Others & 1 & 4 \\
> l organism & 3 & 5 \\
No organism & 10 & \\
\hline
\end{tabular}

Cerebral abcess: 2, endocarditis: 2, osteitis: 2 . fever of unknown origin: 2 , enteritis: 1, erysipelas: 1 .

"Hoemophilus influenzoe: 1, Staphylococcus cureus: 2, Proplonibacter spp:: 1 .

Table III. Incidence of biliary stone (b.s.) or precipitation (b.p.)

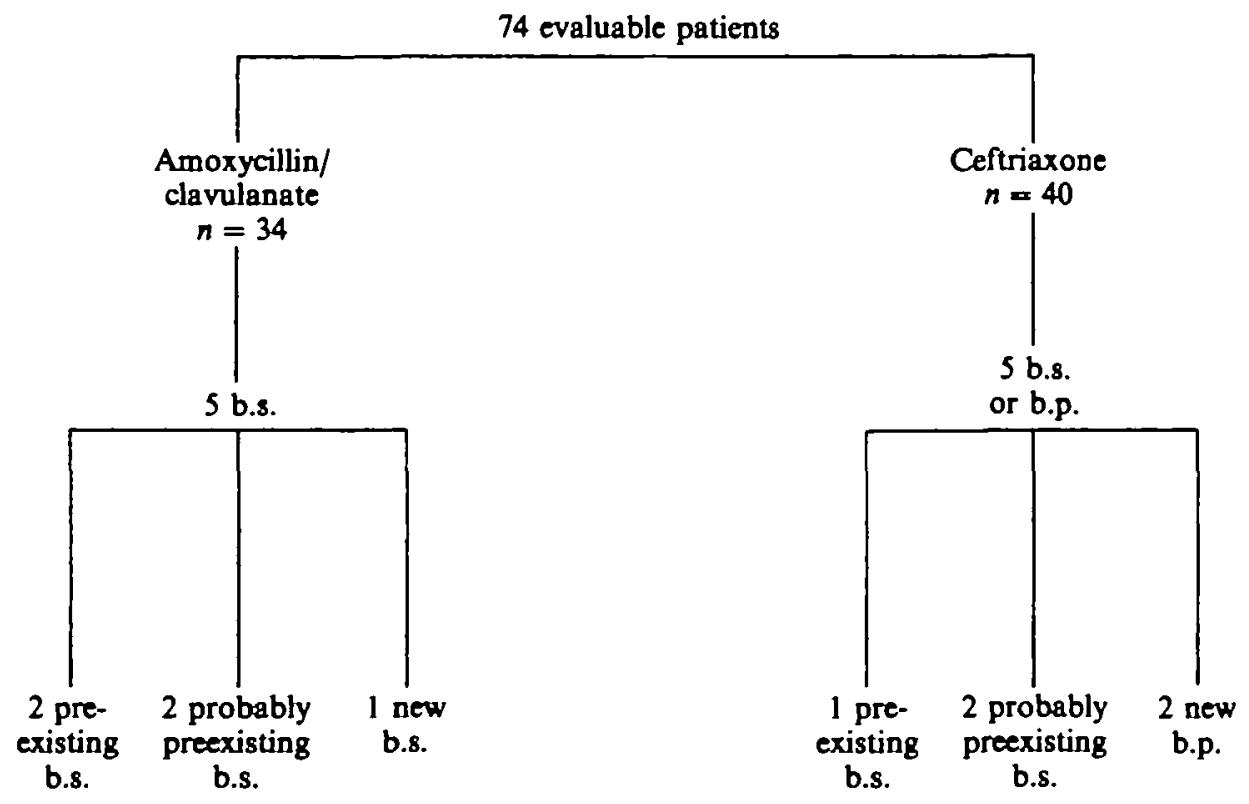


Table III). For one patient in the ceftriaxone group and two patients in the amoxycillin/ clavulanate group the sonography performed at days -1 and 0 showed a calculus, so that lithiasis preceded antibacterial treatment. For two patients in each group, the lithiasis was probably preexisting, although the first control sonography was not performed until two to six days after treatment began: for these four patients, neither the size nor the number of calculi changed during the one year follow-up. In one patient treated with amoxycillin/clavulanate, the gallbladder was not seen at the first control; at six months, a biliary precipitation was observed, but this had been noted in an ultrasonography performed two years before the study.

In one patient receiving ceftriaxone, three small calculi and a biliary precipitation were seen one day after treatment started. The calculi were still present at further evaluation but the biliary precipitation was not described any more. In another patient who received ceftriaxone for 15 days for an $E$. coli pyelonephritis, biliary ultrasonography performed at the end of ceftriaxone treatment for a reason other than biliary symptomatology, showed biliary precipitation: while this patient did not return for the six months follow-up, the biliary ultrasonography was normal at 12 months.

Gallbladder lithiasis developed during the follow-up in one patient treated with amoxycillin/clavulanate for an enteritis in whom the sonography control at six months was normal, but a calculus was seen in the fundus at 12 months.

\section{Discussion}

Unlike many cephalosporins, ceftriaxone is only partially eliminated by the kidneys: the other elimination pathway is biliary and is responsible for the high therapeutic potential of ceftriaxone in biliary tract infections. Studies (Hayton et al., 1986; Hayton \& Stoeckel, 1986) in patients in whom a T-drain was placed after cholecystectomy showed that $10-20 \%$ of the ceftriaxone injected was eliminated by the bile; this was similar to observations in volunteers in whom the ceftriaxone levels were measured in duodenal aspirate. Tolerance studies in dogs and monkeys (Teelmann et al., 1982) given high doses of ceftriaxone for prolonged periods of time have shown that precipitates could appear in the gallbladder of some animals: these precipitates contained 30-50\% taurocholic acid, 10\% lecithin and 30-40\% calcium salts of ceftriaxone. These events were observed in dogs and monkeys given high doses of ceftriaxone (100 and $400 \mathrm{mg} / \mathrm{kg} /$ day), when ceftriaxone was administrated for 4 and 26 weeks respectively.

Like ceftriaxone, cefoperazone, another third generation cephalosporin, is partly eliminated by the bile, biliary elimination having been estimated to be about $15 \%$ (Kemmerich et al., 1983). To our knowledge, there are no data about an association between cefoperazone and the formation of gallbladder precipitations. Schaad, Tschāppeler \& Lentze (1986) \& Schaad \& Tschaãppeler (1987) have described the transient formation of gallstones in the gallbladder of two children given ceftriaxone therapy, in whom echogenic material was seen during ceftriaxone treatment and disappeared after stopping ceftriaxone. More recently, the same authors performed a prospective study (Schaad, Wedgwood-Krucko \& Tschäppeler, 1988) in which young patients receiving ceftriaxone therapy once-a-day $(100 \mathrm{mg} / \mathrm{kg})$ had serial sonographic evaluations. Transient precipitations (hyperechogenic material with shadow) were found in 16 of 37 patients within 4-22 days after ceftriaxone treatment began. In this small patient population, it seemed that biliary precipitations were more common when ceftriaxone 
was administered by short bolus than with $30 \mathrm{~min}$ infusion administration. Normalized sonograms taken within 2-63 days after the end of ceftriaxone treatment were obtained in all these patients. A control group with 22 patients treated with cefuroxime did not show any ultrasonographic abnormality.

Another prospective trial (Heim-Duthoy et al., 1988) in 24 patients receiving ceftriaxone for 14 days once-a-day ( $30 \mathrm{~min}$ infusion) demonstrated biliary precipitation on day 14 in six of 24 patients; these gallbladder abnormalities resolved spontaneously two to three weeks after the end of ceftriaxone therapy. In the control group receiving a placebo, none of nine patients developed a biliary precipitation.

Situations responsible for gallbladder stasis such as dehydration (Callahan et al., 1982) fasting (Bolondi et al., 1985) or total parenteral nutrition (Roslyn et al., 1983; Messing et al., 1983) are known to further biliary precipitations. Of course, one cannot exclude the presence of these factors in Schaad's and Heim-Duthoy's studies. However, both studies had a control group that did not show any biliary precipitations, so that these studies provide convincing evidence that ceftriaxone treatment could cause transitory biliary precipitations.

The purpose of the present study was not to detect precipitation or stone formation during ceftriaxone treatment (neither phenomena were known at the beginning of the study), but to investigate whether ceftriaxone could be responsible for the formation of gallbladder lithiasis in humans within a one year follow-up. No gallbladder lithiasis developed during the follow-up. Only in two patients treated with ceftriaxone were transient biliary precipitations found: these two patients were asymptomatic, with liver enzyme studies remaining normal. Biliary precipitation was seen in the first patient when he had fasted for ten days before the baseline sonography and he had received only one dose of ceftriaxone. In the second patient, biliary precipitation was discovered after 14 days of ceftriaxone treatment when she had not fasted. Other factors such as dehydration or total parenteral nutrition were absent in these two patients. The small group sizes and the low incidence of lithiasis in the control group mean that the results of the study cannot exclude a small difference in the incidence of lithiasis between the treatment groups. Indeed, given the relatively low number of patients enrolled, the study had a power of $55 \%$ to detect a five-fold increase of biliary stone after ceftriaxone treatment and of $95 \%$ to detect a ten-fold increase.

In conclusion, despite the elimination of ceftriaxone through the bile and the description of ceftriaxone salt precipitates in experimental animals after prolonged administration, ceftriaxone treatment did not lead to gallstone formation more often than an antibiotic not eliminated through the bile in the present study. However, our study design did not allow conclusions about ceftriaxone and the formation of biliary precipitation during treatment.

\section{Acknowledgements}

This work was supported by Hoffman-La Roche (Basel, Switzerland). We thank Dr J.D. Baumgartner and Mrs M. M. Wu for help in statistical analysis, Mrs M. A. Blanc for typing the manuscript.

\section{References}

Baumgartner, J. D. \& Glauser, M. P. (1983). Single daily dose treatment of severe refractory infections with ceftriaxone. Cost savings and possible parenteral outpatient treatment. Archives of Internal Medicine 143, 1868-73. 
Bolondi, L., Gaiani, S., Testa, S. \& Labo, G. (1985). Gallbladder sludge formation during prolonged fasting after gastrointestinal tract surgery. Gut 26, 734-8.

Brogard, J. M., Jehl, F., Paris-Bockel, D., Sini, F., Blickle, J. F., Adloff, M. et al. (1987). La ceftriaxone, céphalosporine à forte élimination hepatique. Schweizerische Medizinische Wochenschrift 117, 1549-59.

Callahan, J., Haller, J. O., Cacciarelli, A. A., Slovis, T. L. \& Friedman, A. P. (1982). Cholelithiasis in infants: association with total parenteral nutrition and furosemide. Radiology 143, 437-9.

Cleeland, R. \& Squires, E. (1984). Antimicrobial activity of ceftriaxone: a review. American Journal of Medicine 77, Suppl. 4C, 3-11.

Cooperberg, P. L. \& Gibney, R. G. (1987). Imaging of the gallbladder, 1987. Radiology 163, 605-13.

Dunnett, C. W. \& Gent, M. (1977). Significance testing to establish equivalence between treatments, with special reference to data in the form of $2 \times 2$ tables. Biometrics 33, 593-602.

Hayton, W. L., Schandlik, R. \& Stoeckel, K. (1986). Biliary excretion and pharmacokinetics of ceftriaxone after cholecystectomy. European Journal of Clinical Pharmacology 30, 445-51.

Hayton, W. \& Stoeckel, K. (1986). Biliary excretion of ceftriaxone. European Journal of Clinical Pharmacology 31, $123-4$.

Heim-Duthoy, K., Caperton, E., Matzke, C. \& Peterson, P. (1988). Biliary pseudolithiasis during ceftriaxone therapy. In Program and Abstracts of the Twenty-Eighth Interscience Conference on Antimicrobial Agents and Chemotherapy. Los Angeles, CA, 1988. Abstract 556, p. 206. American Society for Microbiology, Washington, DC.

Kemmerich, B., Lode, H., Borner, K., Belmega, D., Jendroschek, T., Koeppe, P. et al. (1983). Biliary excretion and pharmacokinetics of cefoperazone in humans. Joumal of Antimicrobial Chemotherapy 12, 27-37.

Messing, B., Bories, C., Kunstlinger, F. \& Bernier, J. J. (1983). Does total parenteral nutrition induce gallbladder sludge formation and lithiasis? Gastroenterology 84, 1012-9.

Patel, I. H. \& Kaplan, S. A. (1984). Pharmacokinetic profile of ceftriaxone in man. American Journal of Medicine 77, Suppl. 4C, 17-25.

Roslyn, J. J., Pitt, H. A., Mann, L. L., Ament, M. E. \& Den Besten, L. (1983). Gallbladder disease in patients on long-term parenteral nutrition. Gastroenterology 84, 148-54.

Schaad, U. B. \& Tschäppeler, H. (1987). Symptomatische, reversible Uretero- und Cholelithiasis unter Therapie mit Ceftriaxon. In Program der Jahresversammleng der Schweizerische Gesellschaft für Paediatrie, Geneva, Switzerland, 1987. Abstract G 7554, p. 141.

Schaad, U. B., Tschappeler, H. \& Lentze, M. J. (1986). Transient formation of precipitations in the gallbladder associated with ceftriaxone therapy. Pediatric Infectious Disease 5, 708-10.

Schaad, U. B., Wedgwood-Krucko, J. \& Tschäppeler, H. (1988). Reversible ceftriaxoneassociated biliary pseudolithiasis in children. Lancet $i i, 1411-3$.

Teelmann, K., Schärer, K. \& Udaka, K. (1982). Experimentelle Toxicologie von Ceftriaxon. In Ceftriaxon. Ein Neues Parenterales Cephalosporin. Proceedings of the 9th HahnenkleeSymposium, 1981 (Grieshaber, R. Ed.), pp. 91-111. Editiones Roche, Basel.

(Received 16 January 1989; revised version accepted 2 November 1989) 